\title{
Synergistic Interactions of the Plant Cell Death Pathways Induced by Phytophthora infestans Nep1-Like Protein PiNPP1.1 and INF1 Elicitin
}

\author{
Thirumala-Devi Kanneganti, Edgar Huitema, Cahid Cakir, and Sophien Kamoun \\ Department of Plant Pathology, The Ohio State University, Ohio Agricultural Research and Development Center, \\ 1680 Madison Ave., Wooster, OH 44691, U.S.A.
}

Submitted 8 June 2005. Accepted 30 March 2006.

Cell death plays a ubiquitous role in plant-microbe interactions, given that it is associated with both susceptible and resistance interactions. A class of cell death-inducing proteins, termed Nep1-like proteins (NLPs), has been reported in bacteria, fungi, and oomycetes. These proteins induce nonspecific necrosis in a variety of dicotyledonous plants. Here, we describe three members of the NLP family from the oomycete Phytophthora infestans (PiNPP1.1, PiNPP1.2, and PiNPP1.3). Using agroinfection with a binary Potato virus $X$ vector, we showed that PiNPP1.1 induces cell death in Nicotiana benthamiana and the host plant tomato. Expression analyses indicated that PiNPP1.1 is up-regulated during late stages of infection of tomato by $P$. infestans. We compared PiNPP1.1 necrosis-inducing activity to INF1 elicitin, a wellstudied protein that triggers the hypersensitive response in Nicotiana spp. Using virus-induced gene silencing, we showed that the cell death induced by PiNPP1.1 is dependent on the ubiquitin ligase-associated protein SGT1 and the heat-shock protein HSP90. In addition, cell death triggered by PiNPP1.1 but not that by INF1 was dependent on the defense-signaling proteins COI1, MEK2, NPR1, and TGA2.2, suggesting distinct signaling requirements. Combined expression of PiNPP1.1 and INF1 in $N$. benthamiana resulted in enhanced cell death, suggesting synergistic interplay between the two cell-death responses. Altogether, these results point to potentially distinct but interacting cell-death pathways induced by PiNPP1.1 and INF1 in plants.

Additional keywords: effector, hemibiotrophic, necrotrophic, signal transduction.

Cell death plays a ubiquitous role in plant-microbe interactions and can be associated with both susceptible and resistance

T.-D. Kanneganti and E. Huitema contributed equally to this work.

Corresponding author: S. Kamoun;

Telephone: +1.330.263.3847; Fax: +1.330.263.3841;

E-mail: kamoun.1@osu.edu; Interrnet: http://www.KamounLab.net

Nucleotide sequence data for PiNPP1.1, PiNPP1.2, and PiNPP1.3 is available in the GenBank database under accession numbers AY961417, AY961431 and AY961432, respectively.

*The $\boldsymbol{e}$-Xtra logo stands for "electronic extra" and indicates the HTML abstract available on-line contains supplemental material not included in the print edition. responses. Indeed, the effect of cell death on the outcome of a particular plant-pathogen interaction varies depending on the mode of infection of the pathogen and the pathosystem in question (Bonas and Lahaye 2002; Dickman et al. 2001). For example, $R$-gene mediated disease resistance and many types of nonhost resistance involve the hypersensitive response (HR), a form of programmed cell death in plants that is particularly effective against pathogens that require living host cells (so-called biotrophs) (Dangl and Jones 2001; Dangl et al. 1996; Heath 2000; Kamoun et al. 1999b; McDowell and Woffenden 2003). In contrast, necrotrophic pathogens that obtain nutrients from dead plant tissue trigger programmed cell death in host plants to facilitate colonization (Asai et al. 2000; Dickman et al. 2001; Govrin and Levine 2000; McDowell and Woffenden 2003; Navarre and Wolpert 1999; Wang et al. 1996). The ambiguous role of cell death is particularly evident in hemibiotrophic pathogens, such as the oomycetes Phytophthora infestans and $P$. sojae. These pathogens adopt a two-step infection style. During the phase of infection that follows penetration of host tissue, they require living cells, much like biotrophic pathogens. In contrast, in a later phase of the disease, they cause extensive necrosis of host tissue, resulting in profuse colonization and sporulation. This infection cycle suggests that host cell death may differently impact the disease depending on timing of occurrence. Furthermore, the extent to which different cell-death pathways regulate the HR and disease associated necrosis remains unclear.

In recent years, a novel class of necrosis-inducing proteins, known as Nep1-like proteins (NLPs) (Pemberton and Salmond 2004), have been identified in bacteria, fungi, and oomycetes. These proteins, named after the canonical $24-\mathrm{kDa}$ necrosisand ethylene-inducing protein (Nep1) that was originally purified from culture filtrates of Fusarium oxysporum f. sp. erythroxyli (Bailey et al. 1997), have been described from species belonging to genera as diverse as Bacillus (Takami and Horikoshi 2000), Erwinia (Bell et al. 2004; Pemberton et al. 2005), Verticillium (Wang et al. 2004), Pythium (Veit et al. 2001), and Phytophthora (Fellbrich et al. 2002; Qutob et al. 2002). Despite their diverse phylogenetic distribution, NLPs share a high degree of sequence similarity, and several members of the family have the ability to induce cell death in as many as 20 dicotyledonous plants (Bailey 1995; Bailey et al. 1997; Pemberton and Salmond 2004). The contribution of NLPs to disease remains unclear at this stage. NLPs induce defense responses in both susceptible and resistant plants, and therefore, are thought of as general or nonspecific elicitors. 
Based on similarity to self and nonself recognition models of the animal innate immune system, general elicitors such as NLPs have been likened to pathogen-associated molecular patterns (PAMPs) (Nurnberger and Brunner 2002). NLPs fulfill some criteria for functioning as PAMP triggers of nonself immunity in plants, including the occurrence of functional orthologs in a diverse array of pathogenic oomycetes, fungi, and bacteria but absence in plant genomes (Fellbrich et al. 2002; Qutob et al. 2002; Veit et al. 2001; Win et al. 2006). Nevertheless, in $P$. sojae, the PsojNIP gene was expressed late during the colonization of soybean, and thus, may function as a toxin that facilitates colonization of host tissue during the necrotrophic phase of infection (Qutob et al. 2002). This hypothesis is supported by a recent report in which disruptions of the $N I P_{\text {ecc }}$ and NIP eca genes in Erwinia carotovora subsp. carotovora and E. carotovora subsp. atroseptica, respectively, resulted in reduced virulence phenotypes on potato tubers (Pemberton et al. 2005).

The host factors involved in cell-death signaling triggered by NLPs remain poorly understood. Plants accomplish recognition of pathogen molecules through a large set of endogenous receptor-like proteins ( $\mathrm{R}$ proteins) that can either bind effectors or monitor their activity resulting in the HR (Dangl and Jones 2001). Characterization of the genetic requirements for the HR has culminated in models that explain effector recognition and subsequent resistance signaling through tightly controlled multistep cascades. Despite the large number of identified $R$ genes, there are only a small number of known signaling components downstream of protein recognition, pointing to a set of shared signaling steps in plants (Feys and Parker 2000). Among such signaling components, the ubiquitin ligase-associated protein SGT1 is required for a multitude of $R$ gene-mediated HR pathways (Austin et al. 2002; Azevedo et al. 2002; Peart et al. 2002). SGT1 interacts with the COP9 signalosome and was recently shown to interact with RAR1 and the molecular chaperone HSP90, suggesting the presence of multiprotein complexes involved in resistance signaling (signalosomes) (Takahashi et al. 2003). In this model, SGT1 as well as RAR1 function as cochaperones, folding and stabilizing signalosome protein complexes (Takahashi et al. 2003). Localized resistance interactions or wounding can result in systemic induction of elevated defense. Salicylic acid (SA) and jasmonic acid (JA) are important secondary metabolites that participate in induction of systemic acquired resistance and induced systemic resistance, respectively. Recently, COI1, an important regulator of JA-mediated responses, was found to interact with ASK1 as well as ASK2 in the formation of at least two separate $\mathrm{SCF}^{\mathrm{coi}}$ ubiquitin-ligase complexes, presumably regulating JA signaling via ubiquination in planta (Feng et al. 2003; Xu et al. 2002). These results provide a possible direct connection between signalosome complexes and regulation of defense pathways mediated through systemic secondary signals. Whether there are cell-death or HR pathways independent of signalosome protein complexes remains unclear. In particular, we do not know the extent to which the biochemical components involved in NLP response overlap with those mediated by $\mathrm{R}$ proteins.

The NLP family is unusual in many respects. Unlike other pathogen elicitors of cell death, it is remarkably conserved in different phyla. Many questions about the role of these proteins during plant-microbe interactions remain unanswered. Do NLPs function as PAMPs or toxins? Do they trigger resistance or do they facilitate colonization in the late stages of infection? These questions prompted us to characterize NLPs in the well-established $P$. infestans-Solanum pathosystem. Here, we describe three members of the NLP family in $P$. infestans (PiNPP1.1, PiNPP1.2, and PiNPP1.3) and compare their activ- ity with the well-characterized HR elicitor INF1. Using Potato virus $X$ (PVX) agroinfection assays, we show that PiNPP1.1 induces a rapid and potent necrosis in Nicotiana benthamiana and in the host plant tomato. Expression analyses indicated that PiNPP1.1 is differentially expressed throughout infection of tomato by $P$. infestans and is up-regulated during late stages of infection. We used virus-induced gene silencing (VIGS) to identify signaling and regulatory components that contribute to NLP-induced cell death. These analyses showed that cell-death induction depends on the ubiquitin ligase-associated protein SGT1 and the heat-shock protein HSP90. In addition, we showed that COI1, MEK2, NPR1, and TGA2.2 contribute to PiNPP1.1- but not INF1-induced cell death. Finally, we demonstrated synergistic interplay between INF1 and NLPinduced pathways through transient coexpression assays in $N$. benthamiana. Altogether, these results suggest that NLPs may induce cell death through a distinct pathway as compared with a typical HR elicitor such as INF1.

\section{RESULTS}

\section{PiNPPs are members of the NLP family.}

We mined expressed sequence tag (EST) data sets from $P$. infestans (Kamoun et al. 1999a; Randall et al. 2005), using PexFinder to identify cDNAs encoding extracellular proteins and likely to encode effector proteins (Torto et al. 2003). ESTs corresponding to putative extracellular proteins were annotated by similarity and motif searches against public databases. Sequences derived from three cDNAs, named PiNPP1.1, PiNPP1.2, and PiNPP1.3 showed significant similarity to members of the NLP family, including NLPs from $P$. sojae (Qutob et al. 2002) and Phytophthora parasitica (Fellbrich et al. 2002). Sequence analysis revealed open reading frames of 717,738 , and $738 \mathrm{bp}$ corresponding to a predicted translated product of 238, 245, and 245 amino acids for PiNPP1.1, PiNPP1.2, and PiNPP1.3, respectively. SignalP v 3.0 (Bendtsen et al. 2004) analysis of the predicted proteins identified N-terminal signal peptides of 19 amino acid residues with significant mean $\mathrm{S}$ values of $0.750,0.855$, and 0.910 and hidden Markov model scores of 1.0, 0.999, and 0.998 for PiNPP1.1, PiNPP1.2, and PiNPP1.3, respectively.

\section{PiNPP1.1 induces necrosis in $N$. benthamiana and tomato.}

To ectopically express the PiNPP cDNAs in planta, we performed PVX agroinfection assays using the binary vector pGR106 (Lu et al. 2003). Agroinfection of N. benthamiana plants (four-leaf stage) with Agrobacterium tumefaciens GV3101 carrying the construct pGR106-PiNPP1.1 resulted in necrosis at the inoculated sites 4 to 5 days postinfection (dpi), similar to the pGR106-INF1 construct that expresses the wellstudied $P$. infestans elicitin INF1 (Kamoun et al. 1997, 1998) (Fig. 1A). Hypersensitive cell death is typically associated with the accumulation of autofluorescent compounds. To visualize the accumulation of such compounds, we examined the inoculated sites under UV light (480/40 nm excitation filter, 510 barrier nm). Both the PiNPP1.1 and INF1 constructs resulted in increased autofluorescence associated with the necrotic areas (Fig. 1A). In contrast, repeated inoculations with the empty vector pGR106, pGR106-PiNPP1.2, and pGR106-PiNPP1.3 did not produce necrosis or autofluorescence.

We also tested the host plant tomato for response to the PiNPPs. Inoculation of 3- to 5-week-old tomato plants with $A$. tumefaciens carrying PGR106-PiNPP1.1 resulted in necrosis and autofluorescence at 5 dpi (Fig. 1B). At 8 to 9 dpi, necrotic lesions started to spread throughout the entire plant, leading to death (Fig. 1C). None of the other examined constructs caused necrosis in tomato. 
Comparative analyses of necrosis-inducing activity.

We compared the timing and appearance of PiNPP1.1induced cell death to those of known defense-response elicitors, such as the $P$. infestans elicitin INF1 (Kamoun et al. 1997, 1998), as well as NLP family members PsojNIP of $P$. sojae (Qutob et al. 2002) and Nep1 of F. oxysporum (Bailey 1995). A. tumefaciens carrying pGR106-derived constructs were inoculated side-by-side onto fully expanded leaves of $N$. benthamiana and tomato. In $N$. benthamiana, dark necrotic le-

A
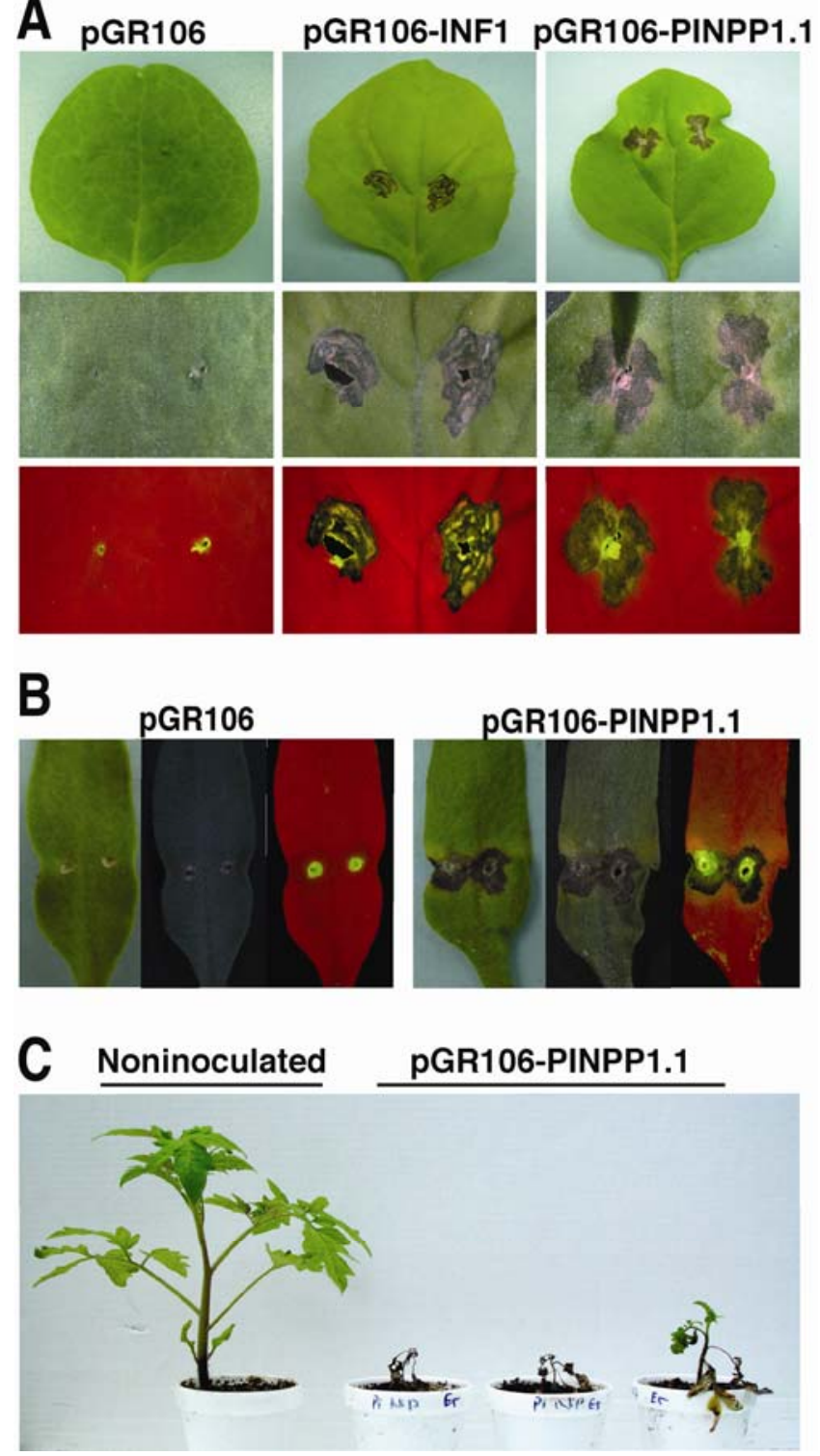

Fig. 1. A, Symptoms observed on Nicotiana benthamiana leaves following inoculation with Agrobacterium tumefaciens strains harboring recombinant Potato virus $X$ (PVX) constructs pGR106 (vector), pGR106-INF1, and pGR106-PiNPP1.1. Upper panels show symptoms observed on entire leaves. Middle and lower panels show symptoms at inoculated sites observed with a dissecting microscope under white light (middle) to visualize cell death and UV light (lower) to visualize cell death-associated autofluorescence. B, Symptoms observed on tomato cotyledons following inoculation with recombinant PVX constructs pGR106 and pGR106PiNPP1.1. Left panels show symptoms observed on entire cotyledons. Middle and right panels show symptoms observed with a dissecting microscope under white light (middle) or UV light (right). C, Spreading necrosis and death of tomato plants after inoculation with A. tumefaciens carrying pGR106-PiNPP1.1. One tomato plant inoculated with pGR106 vector construct (left) and three plants inoculated with pGR106-PiNPP1.1 (right) are shown. Pictures were taken 14 days after inoculation. sions and associated UV autofluorescence were observed at the site of inoculation with pGR106-PiNPP1.1, pGR106PsojNIP, and pGR106-NEP1 within 5 dpi (Fig. 2A), whereas necrosis was only observed starting at 7 dpi with the pGR106INF1 construct (Fig. 2C). On tomato, necrotic symptoms developed at PiNPP1.1-, PsojNIP-, and Nep1-challenged sites 7 dpi (Fig. 2B). No response to the INF1 construct was observed in tomato confirming earlier observations that this protein does not elicit cell death in tomato (Kamoun et al. 1997, 1998). In both plant species, UV autofluorescence was detected at necrotic sites only. These results suggest that PiNPP1.1 is a potent inducer of cell death in both $N$. benthamiana and the host plant tomato.

\section{PiNPP1.1, PiNPP1.2, and PiNPP1.3 are expressed during infection.}

We used semiquantitative reverse transcription polymerase chain reaction (RT-PCR) to determine the expression patterns of PiNPP1.1, PiNPP1.2, and PiNPP1.3 during a time-course infection of tomato by $P$. infestans and to compare them with

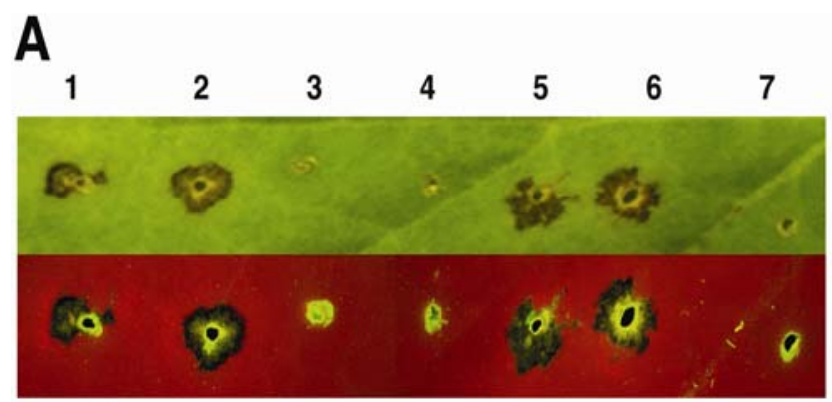

B
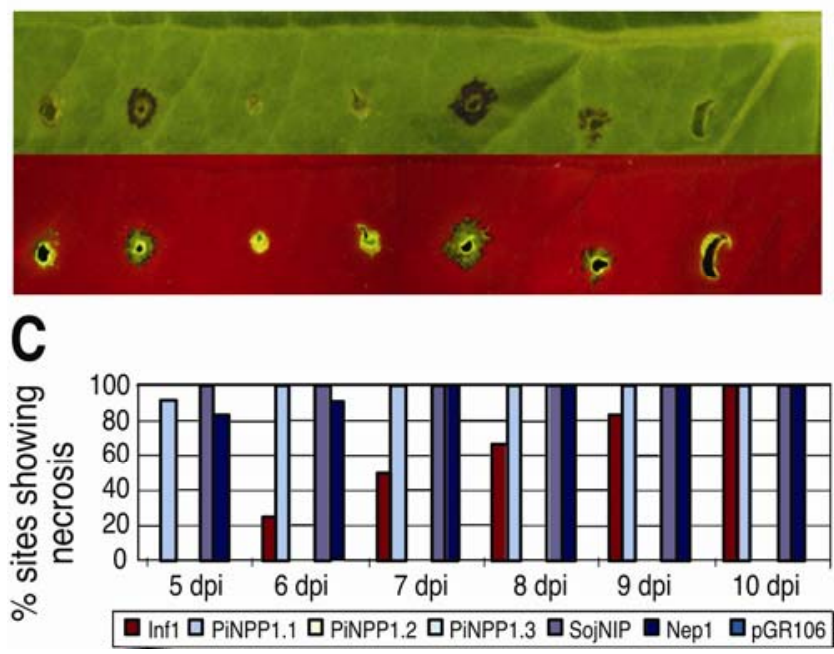

Fig. 2. Comparative analysis of Phytophthora infestans elicitin (INF1); $P$. infestans necrosis-inducing Phytophthora protein 1 (PiNPP1.1), PiNPP1.2, PiNPP1.3; P. sojae necrosis-inducing protein, PsojNIP; F. oxysporum necrosis- and ethylene-inducing peptide, Nep1, inoculated side by side on $\mathbf{A}$, Nicotiana benthamiana and $\mathbf{B}$, tomato. Leaves were wound-inoculated at the leaf base flanking the main vein using recombinant Agrobacterium tumefaciens strains harboring the following Potato virus $X$ vector constructs: pGR106-INF1 (1), pGR106-PiNPP1.1 (2), pGR106-PiNPP1.2 (3), pGR106-PiNPP1.3 (4), pGR106-PsojNIP (5), pGR106-NEP1 (6), and the empty vector pGR106 (7). Responses were documented under white light (top panels) to visualize cell death and under UV light (bottom panels) to visualize cell death-associated autofluorescence. C, Frequencies of inoculation sites showing necrosis observed in $N$. benthamiana leaves from 5 to 10 days postinoculation. Frequencies were calculated and expressed as percentages of necrotic sites of the total number of inoculations per tested construct. The data originated from one representative experiment. 
in vitro-grown mycelium (Fig. 3). cDNA obtained from healthy tomato leaves served as a negative control. Sequence-specific primers were used to ensure exclusive amplification of each gene. RT-PCR analysis revealed that PiNPPl.1 transcripts accumulated during late stages of infection and were significantly up-regulated compared with in vitro-grown mycelium. PiNPP1.1 transcripts were first detected at 3 dpi but dramatically increased at $4 \mathrm{dpi}$. The in planta expression pattern of PiNPP1.2 was similar to PiNPP1.1, but this gene was not up-regulated in planta relative to mycelium. PiNPP1.3 appeared constitutively expressed and showed amplification patterns similar to the constitutive $P$. infestans gene elongation factor 2 (ef2). These results show that PiNPP1.1 exhibits an expression pattern that features significant upregulation in the late stages of infection of tomato relative to mycelium. This expression pattern is similar to the expression of the P. sojae PsojNIP gene during infection of soybean (Qutob et al. 2002) and contrasts with the expression levels of PiNPP1.2 and PiNPP1.3.

\section{PiNPP1.1-induced cell death is dependent} on SGT1 and HSP90.

Previous studies have shown that the ubiquitin ligase-associated protein SGT1 (Peart et al. 2002) and heat-shock protein HSP90 (Kanzaki et al. 2003) are required for HR induction by the $P$. infestans elicitin INF1 in $N$. benthamiana. We tested whether SGT1 and HSP90 are required for PiNPP1.1-induced cell death using VIGS with Tobacco rattle virus (TRV), followed by agroinfiltration assays (Huitema et al. 2004). For this purpose, young $N$. benthamiana plants (five-leaf stage) were infiltrated with mixtures of A. tumefaciens strains carrying combinations of pBINTRA6 (TRV RNA1) and pTV:00, pTV-SGT1, or pTV-HSP90 (TRV RNA2). Three weeks after TRV inoculation, silenced plants were infiltrated with A. tumefaciens strains containing p35S-INF1 and p35S-PiNPP1.1. Recombinant $A$. tumefaciens containing the empty vector pCB302-3 was used as a negative control. Infiltration sites were evaluated 2 and 3 days after infiltration, and frequencies of infiltrated panels showing necrosis were recorded (Fig. 4). Silencing of SGT1 and HSP90 resulted in significant reductions of the proportion of necrotic panels induced by all tested effectors. This suggests that similar to INF1, PiNPP1.1 and PsojNIP require SGT1 and HSP90 to elicit cell death in $N$. benthamiana. These experiments were performed several times, and similar results were obtained. Averages and standard errors of the data shown in Figure 4 were calculated from three independent experimental treatments.

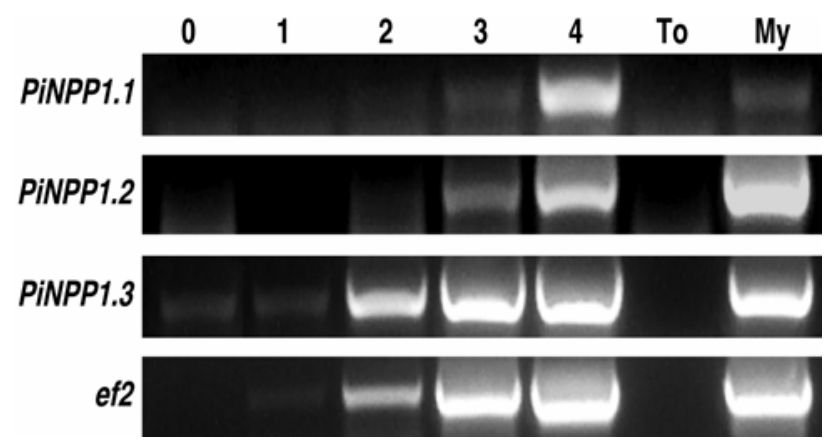

Fig. 3. Semiquantitative reverse transcription polymerase chain reaction analysis of PiNPP gene expression during colonization of tomato. Total RNA was isolated from tomato leaf disks harvested $0,1,2,3$, and 4 days after drop inoculation with zoospore suspensions from Phytophthora infestans (isolate 90128), from noninfected leaves (To), and from P. infestans mycelium grown in synthetic medium (My). Amplification of $P$. infestans elongation factor 2 gene (ef2) was used as a control to determine constitutive levels of expression. Approximate sizes of the transcripts are $492 \mathrm{bp}$ for PiNPP1.1, 693 bp for PiNPP1.2, 693 bp for PiNPP1.3, and 700 bp for ef 2.
COI-1, MEK2, NPR1, and TGA2.2 contribute

to PiNPP1.1- but not INF1-induced cell death.

To further compare INF1- and PiNPP1.1-induced cell death, we elected to silence additional disease-resistance signaling components and test their importance in effector-elicited cell death. For this purpose, we selected and cloned gene fragments representing Coil, Mek2, Tga2.2, and Nprl in pTV00 and tested their involvement in PiNPP1.1-induced cell death. Plants at the four- to five-leaf stage were infiltrated with mixtures of recombinant $A$. tumefaciens strains carrying the binary pBINTRA6 (TRV RNA1) and pTV00, pTV-COI1, pTV-NPR1, pTV-TGA2.2, or pTV-MEK2 (TRV RNA2). Three weeks after inoculation with TRV, silenced plants were infiltrated with $A$. tumefaciens strains containing p35S-INF1 and p35SPiNPP1.1. A recombinant strain containing the empty pCB302-3 vector was used as a negative control. Infiltration sites were scored 2 and 3 days after infiltration for development of cell death. Leaves silenced for COI1, MEK2, NPR1, and TGA2.2 showed consistent reduction in the frequency of panels that responded to PiNPP1.1 as compared with the control plants (Fig. 5). In contrast to PiNPP1.1, no reduction in cell death induced by INF1 was noted in any silenced plants. These results suggest differences in signal requirements between

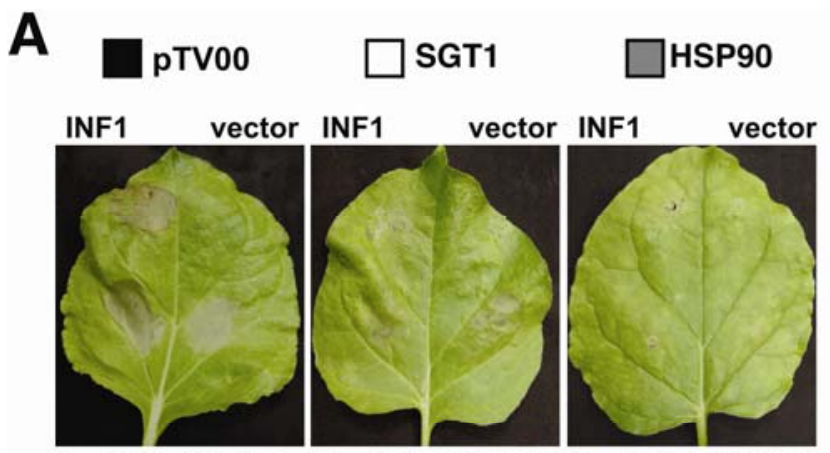

PsojNIP PiNPP1.1 PsojNIP PiNPP1.1 PsojNIP PiNPP1.1

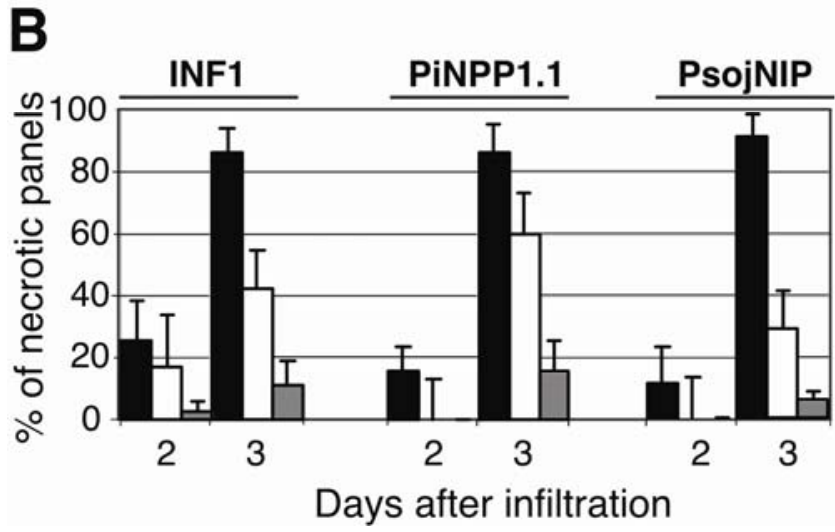

Fig. 4. PiNPP1 induces SGT1 and HSP90-dependent cell death. Nicotiana benthamiana plants were infiltrated with mixtures containing Agrobacterium tumefaciens pBINTRA6 (TRV RNA1) and pTV00 (TRV), pTVSGT1 (TRV-SGT1), or pTV-HSP90 (TRV-HSP90) to trigger Tobacco rattle virus (TRV)-induced gene silencing. Three weeks after TRV inoculation, silenced leaves were infiltrated with recombinant A. tumefaciens strains containing p35S-INF1, p35S-PiNPP1.1, or the empty vector (pCB302-3). A, Symptoms observed on silenced leaves 3 days after the secondary challenge with A. tumefaciens carrying p35S-INF1, p35SPiNPP1.1, or the empty vector. B, Percentage of necrotic panels after secondary agroinfiltration with the INF1, PiNPP1.1, and PsojNIP constructs. Percentages were determined on control as well as SGT1- and HSP90silenced plants for each treatment and were scored two and three days after the secondary challenge. Averages and standard errors were calculated from three independent experimental treatments. 
INF1- and PiNPP1.1-induced cell deaths, pointing to the potential occurrence of separate cell-death signaling pathways. Averages and standard errors of the data in Figure 5 were calculated from two independent experimental treatments.

\section{Coexpression of inf1 and PiNPP1.1 leads} to synergistic enhancement of cell death.

To further test the relationships between INF1- and PiNPP1.1-induced signaling pathways, we performed mixed agroinfiltration experiments in $N$. benthamiana. For further comparisons, we also included the $P$. sojae NLP PsojNIP. To enable the detection of antagonistic or synergistic effects be-

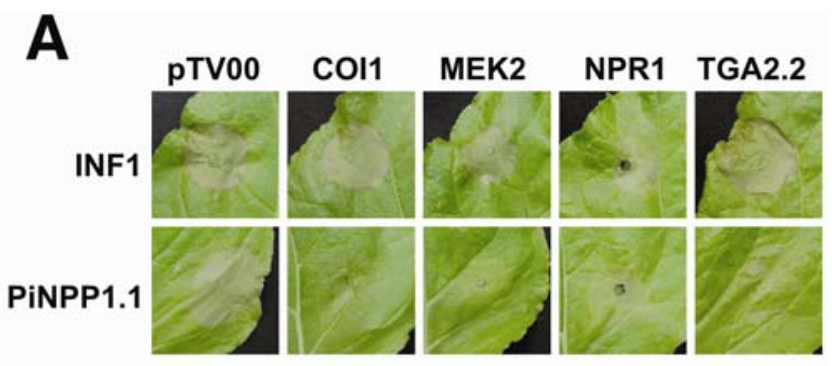

B

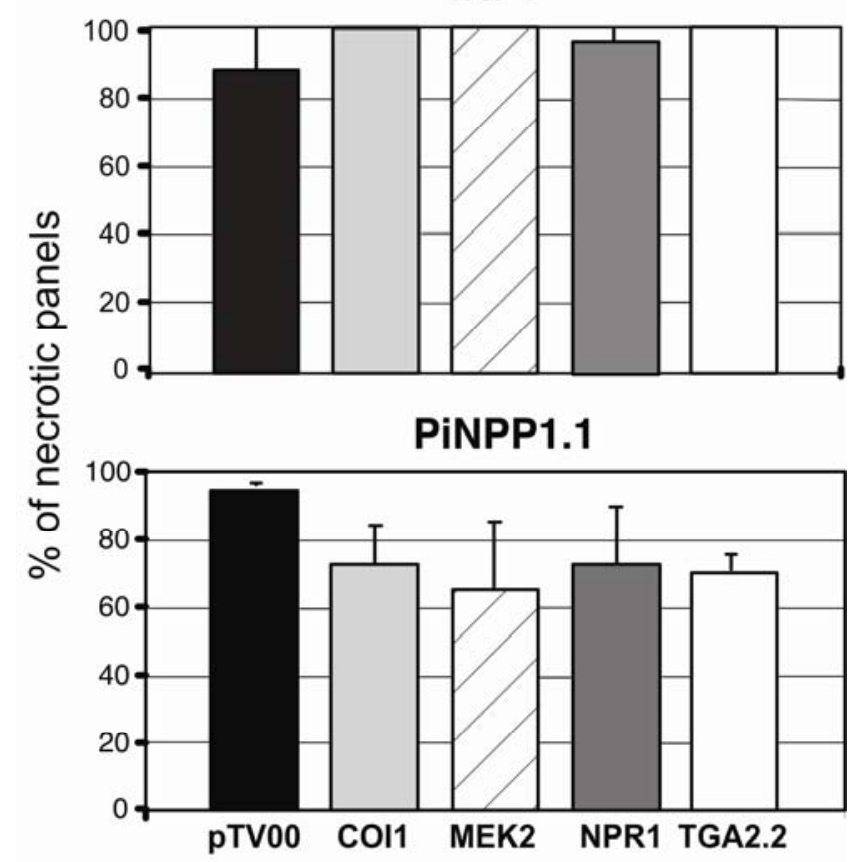

3 days postinfiltration

Fig. 5. COI1, MEK2, TGA2.2, and NPR1 contribute to the cell death triggered by PiNPP1.1 but not by INF1. Nicotiana benthamiana plants at the four- to five-leaf stage were infiltrated with mixtures of recombinant Agrobacterium tumefaciens strains carrying the binary construct pBintra6 (TRV-RNA1) and pTV00, pTV-COI1, pTV-MEK2, pTV-NPR1, or pTVTGA2.2 (TRV-RNA 2) to trigger Tobacco rattle virus (TRV)-induced gene silencing. Three weeks after TRV inoculation, silenced leaves were infiltrated with recombinant $A$. tumefaciens strains containing p35S-INF1, p35S-PiNPP1.1, and pCB302-3 (negative control). A, Symptoms observed 3 days after secondary challenge on control leaves (pTV00) and leaves silenced for COI-1, MEK2, NPR1, and TGA2.2. B, Percentage of panels showing necrosis after secondary agroinfiltration with the INF1 and PiNPP1.1 constructs. Percentages were determined on control as well as COI1-, MEK2-, NPR1-, and TGA2.2-silenced plants for each treatment and three days after the secondary challenge. Averages and standard errors were calculated from two independent experimental treatments. tween the effectors, we determined the concentration threshold that resulted in significant reductions of necrosis frequencies by infiltrating $N$. benthamiana leaves with dilution series of $A$. tumefaciens containing p35S-INF1, p35S-PiNPP1.1, and p35SPsojNIP (data not shown). It turned out that A. tumefaciens carrying p35S-INF1 had the lowest subnecrotic optical density at $600 \mathrm{~nm}\left(\mathrm{OD}_{600}\right)$ (approximately 0.2), and we used this value for all strains in mixed infiltration experiments. Early experiments aimed at identifying antagonistic (suppression) effects between INF1 and the NLPs were not successful, so we focused on evaluating synergistic relationships. A. tumefaciens carrying p35S-INF1 was mixed with strains carrying p35S-PiNPP1.1 or p35S-PsojNIP (1:1 ratio), and the mixtures were infiltrated side-by-side with individual strains on $N$. benthamiana leaves (final $\mathrm{OD}_{600}=0.2$ ). Infiltrated panels were evaluated and scored for cell death 1, 2, and 3 days after infiltration. Percentage of necrosis development was calculated (number of panels showing necrosis/total number of panels infiltrated $\times 100$ ) per treatment for every comparison. Pair-wise comparisons revealed distinct differences in timing and intensity of cell death between the various treatments (Fig. 6A). A total of 39 and $54 \%$ of the leaf panels infiltrated with the mixture of INF1 and PiNPP1.1 strains, and 65 and $80 \%$ of the panels infiltrated with the INF1 and PsojNIP mixture showed cell death as early as 2 days after infiltration (Fig. 6B). In contrast, infiltrations with individual $A$. tumefaciens strains resulted in 8,3, and $16 \%$ rates of cell-death elicitation for the INF1, PiNPP1.1, and PsojNIP, respectively. Differences were sustained 3 days after infiltration with the INF1 and NLP strain mixtures resulting in frequencies of celldeath elicitation over $90 \%$, whereas the individual treatment resulted in cell-death induction in less than $40 \%$ of the infiltration sites (Fig. 6B). Averages and standard errors of the data in Figure 6 were calculated from two independent experimental treatments. These results are consistent with the hypothesis that INF1 and the NLPs trigger cell death through distinct celldeath pathways and suggest a synergistic interaction between the cell-death responses induced by INF1 and the NLPs.

\section{DISCUSSION}

Plant pathogenic microbes manipulate cellular and biochemical processes in their host plants through a diverse array of effectors that can promote infection (virulence factors) or trigger defense responses (elicitors or avirulence factors). Our laboratory is engaged in functional screens of candidate genes to identify effectors from $P$. infestans, particularly those that induce plant cell death (Torto et al. 2003). As part of these screens, we identified three cDNAs from $P$. infestans with significant similarity to NLP family proteins. One of these, PiNPP1.1, induced necrosis in both the host plant tomato and $N$. benthamiana. Expression analyses of the PiNPP1.1 gene showed that it is up-regulated during late stages of colonization of tomato, similar to the P. sojae NLP PsojNIP (Qutob et al. 2002). We found that cell death triggered by INF1 and PiNPP1.1 required SGT1 and HSP90. In contrast, COI1, MEK2, NPR1, and TGA2.2 contributed to PiNPP1.1- but not INF1-induced cell death. We also determined that coexpression of INF1 with either PiNPP1.1 or PsojNIP led to intensified and accelerated cell death. Taken together, we conclude that PiNPP1.1- and INF1-induced cell death may result from distinct signaling cascades and suggest synergistic signaling interactions between pathways. Although the exact mechanisms of signaling interplay remain unclear, these results point to extensive cellular reprogramming events in plant cells during Phytophthora-host interactions.

NLPs are widely distributed among plant pathogenic oomycetes and fungi as well as plant-associated bacteria, suggesting 
that they play central roles in plant parasitic lifestyles (Pemberton and Salmond 2004; Win et al. 2006). In P. infestans and $P$. sojae, NLPs form gene families with only a single member capable of triggering cell death (Qutob et al. 2002; this study). Interestingly, these and other NLPs evoke complex defense responses and cell death in a diverse range of dicotyledonous plant species, such as tomato, parsley, tobacco, Arabidopsis, and soybean (Fellbrich et al. 2002; Qutob et al. 2002; this study). NLPs may therefore be considered PAMPs that upon recognition trigger innate defense mechanisms in dicotyledonous plants.

Of the three PiNPP genes, PiNPP1.1 was significantly upregulated during the later stages of infection, and its expression pattern resembles that of the PsojNIP gene (Qutob et al. 2002). Elevation of transcript levels may therefore correlate with the transition from biotrophy to the destructive necrotrophic phase, indicating that PiNPP1.1 as well as PsojNIP, rather than being PAMPs, may function as toxins. If true, tissue collapse could suppress defenses and facilitate colonization during the late phase of infection. These findings raise the possibility that downregulation of NLP genes during the early phase of infection followed by upregulation during the necrotrophic phase is a common feature in hemibiotrophic Phytophthora spp. A role for PiNPP1.1 in virulence is consistent with the findings of Pemberton and associates (2005), who demon- strated a role for the Erwinia carotovora subsp. carotovora gene $\mathrm{Nip}_{E c c}$ in soft-rot production on potato tubers and showed a contribution of the Erwinia carotovora subsp. atroseptica gene Nip $_{E c a}$ in development of potato stem rot (Pemberton et al. 2005).

NLPs induce complex defense responses and cell death in plants. Biochemical analysis of the activity of necrosis-inducing Phytophthora protein 1 (NPP1) from P. parasitica in cultured parsley cells and protoplasts pointed to convergent signaling with PEP13, a known and well-characterized PAMP from Phytophthora spp. (Fellbrich et al. 2002). To obtain more insights about NLP-induced defense responses, we used VIGS to test the genetic requirements of NLP-induced cell death. We showed that, in addition to the previously characterized elicitin INF1, PiNPP1.1 as well as PsojNIP require both SGT1 and HSP90 for cell-death induction. Recently, SGT1 was proposed to act together with RAR1 as a cochaperone of HSP90, stabilizing and regulating signalosome complexes (Takahashi et al. 2003). It is, therefore, tempting to speculate that both SGT1 and HSP90 are present in signalosome complexes together with receptor-like proteins and other regulatory proteins (e.g., kinases), which participate in NLP-induced signaling. It should be pointed out, however, that HSP90 is thought to have multiple targets, some of which could be involved in alternative cellular processes contributing to cell death. Therefore, we

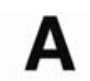

INF1+PiNPP1.1

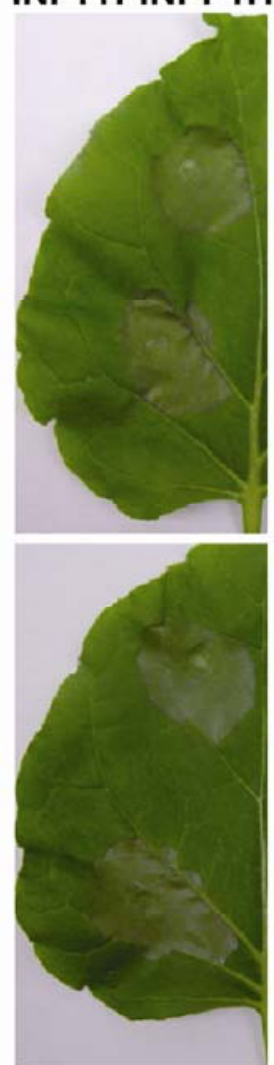

INF1+PsojNIP
INF1
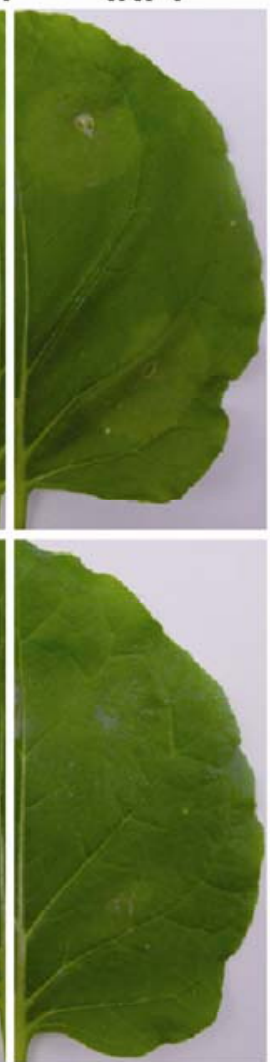

INF1
PiNPP1.1
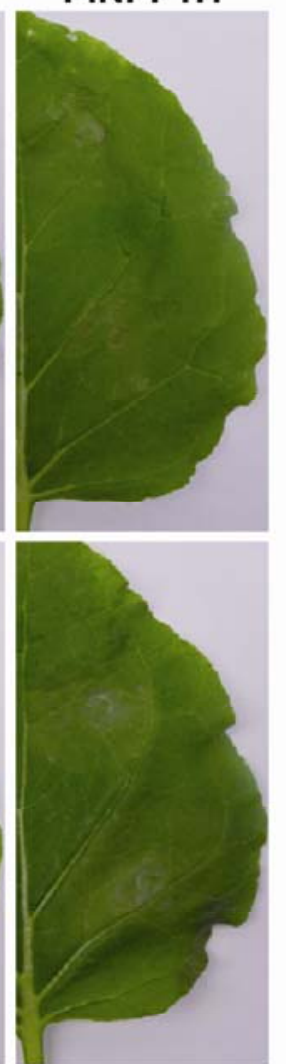

PsojNIP
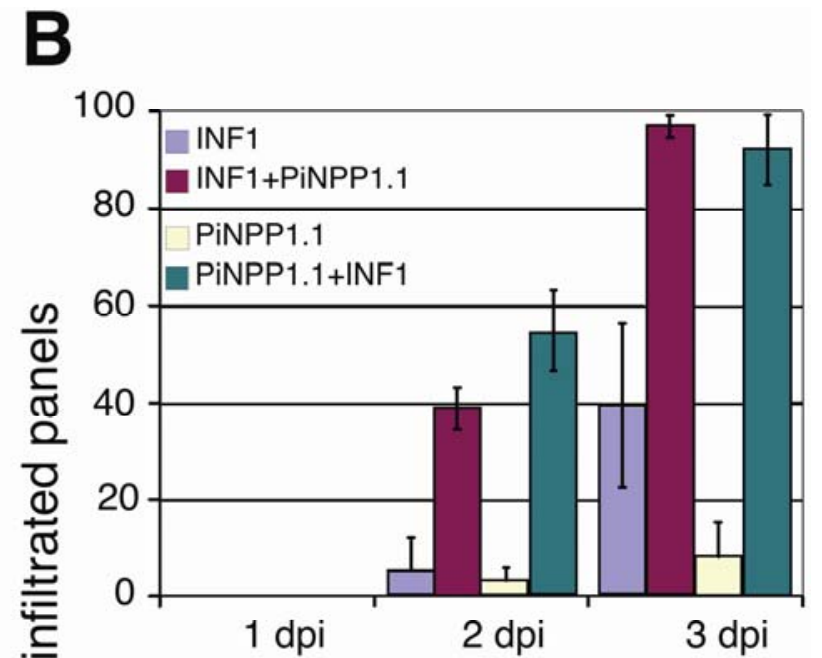

Fig. 6. Coexpression of INF1 and PiNPP1.1 or PsojNIP leads to synergistic enhancement of cell-death elicitation. Mixtures of recombinant Agrobacterium tumefaciens strains carrying p35S-INF1 and p35S-PiNPP1.1 (top of panels A and B) or p35S-INF1 and p35S-PsojNIP (bottom of panels A and B) were infiltrated side-by-side with individual treatments on Nicotiana benthamiana leaves. Infiltrated panels were evaluated and scored for cell-death development 1, 2, and 3 days after infiltration. A, Symptom development three days after infiltration with the INF1 + PiNPP1.1/PsojNIP mixtures, INF1 alone, or PiNPP1.1/PsojNIP alone. Note the enhanced cell death observed in panels infiltrated with the mixtures. B, Percentage of panels showing necrosis after infiltration with the INF1 + PiNPP1.1/PsojNIP mixtures, INF1 alone, or PiNPP1.1/PsojNIP alone at 1, 2, and 3 days after infiltration. Results of two independent experiments were combined to generate average necrosis induction frequencies and standard error values. 
cannot exclude the possibility that HSP90 silencing affected unknown cellular processes, thereby inhibiting cell death. Genetic analyses of the role of additional signalosome components and HSP90 partners will help to clarify this issue.

COI1, MEK2, NPR1, and TGA2.2 were identified as signaling components that contribute to NLP-induced cell death. COII is required for JA-mediated signaling, presumably via $\mathrm{SCF}^{\mathrm{coi}}$-mediated ubiquination in planta (Feng et al. 2003; Xu et al. 2002). It is possible that $\mathrm{SCF}^{\mathrm{coi}}$ complexes play a part in NLP-induced signaling, during which they require HSP90 and SGT1. Expression of PiNPP1.1 in N. benthamiana plants silenced for COI1 interactors ASK1 and ASK2 should help test this possibility. In the present study, MEK2, a mitogen-activated protein kinase (MAPK) kinase, was found to contribute to NLP-induced cell death. MAPK signaling pathways constitute modules of protein kinases that regulate cellular processes and act as molecular switches between pathways. For example, upon elicitor treatment, NtMEK2 activates wounding-induced protein kinase (WIPK) and salicylic acid-induced protein kinase (SIPK) before the onset of the HR (Zhang et al. 2000). These findings combined with our results suggest that NLP expression in planta induces cell death through discrete signaling cascades that include MEK2. Whether WIPK or SIPK are part of a module that regulates NLP-induced cell death remains to be determined.

We also showed that NPR1 and TGA2.2 silencing results in reduced levels of cell-death induction. Both NPR1 and TGA2.2 are transcriptional regulators of defense responses dependent on SA. NPR1 physically interacts with TGA2.2, a requirement for activation of pathogenesis-related gene expression and onset of defense responses (Despres et al. 2000, 2003; Niggeweg et al. 2000). It is, therefore, possible that the NLP-induced cascade is either aided by SA signaling or that it overlaps with some of its signaling steps. The contributions of SA (NPR1 and TGA2.2) and JA (COI-1) signaling genes to NLP-induced cell death point to a potential model for the role of NLP proteins in pathogenesis. NLPs may be functionally analogous to the bacterial phytotoxin coronatine, aiding in pathogen virulence through modulation and jamming of defense signaling pathways (Bender et al. 1999; Feys et al. 1994; Zhao et al. 2003). Indeed, Block and associates (2005) showed that Pseudomonas syringae pv. tomato mutants deficient in coronatine production exhibit reduced virulence on Arabidopsis, suggesting that jamming defense signaling pathways is important for disease development. It should be pointed out, however, that the contribution of SA as well as JA signaling to defense networks in $N$. benthamiana is not as well understood as in Arabidopsis or tomato. In fact, our understanding of defense signaling in $N$. benthamiana is mostly based on extrapolation from tomato. Future studies on JA- and SA-mediated pathways as well as silencing additional SA, JA, and ethylene signaling genes will enhance our understanding of these pathways in $N$. benthamiana. Ultimately, such studies will provide a comprehensive overview of defense and cellular reprogramming in solanaceous plants.

The requirements for NLP-induced cell death was investigated and compared with that of INF1, using VIGS. Our observations point to the existence of separate signaling pathways. Plants have the ability to trigger intricate webs of signaling cascades, enabling appropriate and dosed responses to a multitude of signals. For instance, the RPP4, RPP7, and RPP8 resistance proteins that function against a defined set of Peronospora parasitica isolates have different but overlapping signaling requirements that mediate defense induction (Aarts et al. 1998; Eulgem et al. 2004). To investigate the relationship between signaling pathways, we coexpressed both PiNPP1.1 and PsojNIP with infl and assayed for alterations in cell-death induction. Our results were consistent with the occurrence of two separate signaling cascades and, in addition, suggest synergistic interplay between pathways. Pathogen recognition invariably results in cellular reprogramming. Signaling downstream of pathogen perception can induce transcriptional activation of multiple classes of defense-related genes initially, followed by upregulation of genes that are involved in signal transduction (Eulgem et al. 2004). Similarly, perception of flg22, a flagellin-derived PAMP molecule that induces innate immunity in Arabidopsis, results in upregulation of signaling genes predominantly (Navarro et al. 2004). It is possible that recognition of PAMPs or other pathogen molecules (INF1 or PINPP1.1) leads to sensitization or priming of host cells to other biotic stimuli. Future efforts directed at understanding the role of the signaling genes that are induced by either INF1 or NLPs may help to clarify our understanding of cell sensitization.

In summary, we propose that the $P$. infestans proteins PiNPP1.1 and INF1 represent an example of molecules derived from the same pathogen that induce cell death through potentially distinct signaling pathways. Although many questions remain unanswered, these findings raise some intriguing possibilities with respect to NLP function. Future studies will help to further identify and characterize NLP-specific signaling components and provide more insight into the mechanisms that govern host cell death, pathogenesis, and virulence.

\section{MATERIALS AND METHODS}

\section{Microbial strains and growth conditions.}

P. infestans isolate 90128 (A2 mating type) was used for the timecourse infection assay and was cultured as described earlier (Kamoun et al. 1998). For RNA extraction, plugs of mycelium were transferred to modified Plich medium (Kamoun et al. 1993) and were grown for 2 to 3 weeks before harvesting.

A. tumefaciens GV3101 was used in molecular cloning experiments and was routinely cultured at $28^{\circ} \mathrm{C}$ in Luria-Bertani (LB) media, using appropriate antibiotics (Sambrook and Russell 2001). All bacterial DNA transformations were conducted by electroporation using standard protocols (Sambrook and Russell 2001).

\section{PVX agroinfection and agroinfiltration constructs.}

The cDNA inserts of PiNPP1.1, PiNPP1.2, and PiNPP1.3 were PCR-amplified from their respective cDNA clones using pSPORT-AscI (5'-GGCCGGCGCGCCCTCCCGGGTCGACC CACGCGTCC-3') and SP6 (5'-TACGATTTAGGTGACACTA TAG-3') primers and high-fidelity Pfu DNA polymerase (Stratagene, La Jolla, CA, U.S.A.). The fragments were cloned in the binary PVX vector pGR106 (Lu et al. 2003), using the $\mathrm{ClaI}$ and NotI restriction enzymes, and were transformed into A. tumefaciens GV3101 to generate agroinfection-ready clones. Recombinant clones were tested for the presence of PiNPP inserts by PCR amplification with PVX primers, PVXF (5'- AATCAATCACAGTGTTGGCTTGC-3') and PVX-R (5'-AGTTGACCCTATGGGCTGTGTTG- ${ }^{\prime}$ ), and the inserts were checked by DNA sequencing. pGR106-PSOJNIP, pGR106-NEP1, and pGR106-INF1 were described elsewhere (Qutob et al. 2002; Torto et al. 2003). PiNPP1.1 was cloned into the mini-binary vector pCB302-3 (Xiang et al. 1999) to obtain p35S-PiNPP1.1. For this purpose, PCR amplification was performed from the original cDNA clone using the primers PiNPP1.1-F (5'-GCGACTAGTATGAACATCCTTCAACT CTTCGC-3') and PiNPP1.1-R (5'-GCGACTAGTCTAGGCGT AGTAGGCATTG-3'), adding SpeI restriction sites flanking both termini. Fragments were ligated into predigested pCB302-3 vector and were transformed into A. tumefaciens. Recombinant colonies were tested directly for insertion of the gene in the 
right orientation, using a primer binding to the $35 \mathrm{~S}$ promoter 35S-F (5'-ATGACGCACAATCCCACTATCCTTC-3') and PiNPP1.1-R. Amplified inserts were used for sequence verification.

\section{VIGS constructs.}

TRV:SGT1, which carries a fragment of the NbSGT1.1 gene (GenBank accession number AF516180), was described elsewhere (Peart et al. 2002). We amplified LeHSP90-1 from tomato cDNA, using HSP90-F (5'-GGAGGATCCCGAGGGTC TGTGCAAGGTGATTAAGG-3') and HSP90-R (5'-TCAGGA TCCTCCAATGGTGGCAT-3'). coil, mek2, tga2.2, and $n p r 1$ were amplified from $N$. benthamiana cDNA, using primers from Ekengren and associates (2003) modified as follows: COI1-F, 5'-GAGCCCGGGCGGAGATCTGCCACTTGATAATGGTGT$3^{\prime}$ and COI1-R, 5'-GCGGGATCCAAGGCCTTCATCGGATT CCC-3'; NtMek2-F, 5'-GAGCCCGGGCCTACATCGCCCCA CCGGAAGACT-3' and NtMek2-R, 5'-GCGGGATCCACCCA TCGTACTGTCCATGATTCAGATCTGT-3'; TGA2.2-F, 5'-G AGCCCGGGGACATATTCAGGATAAAAGGGGA-3' ${ }^{\prime}$ and TGA2.2-R, 5'-GCGGGATCCTATTCCCGGGGGCGAGCAA GCCA-3'; NPR1-F, 5'-GAGCCCGGGGAAAGAGCCTAAAA TTGTAGTGTC-3' and NPR1-R, 5'-GCGGGATCCCTATTTC CTAAAAGGGACCTTATT-3'. For LeHSP90 and mek2, amplified fragments were digested with BamHI, whereas for coil, tga2.2, and nprl, BamHI and XmaI were used. Digested fragments were ligated into the pTV00 vector (Ratcliff et al. 2001) to yield pTV-COI1, pTV-MEK2, pTV-NPR1, pTVTGA2.2, and pTV-HSP90 and were transformed into electrocompetent A. tumefaciens cells (strain GV3101). Recombinant strains were tested for having the correct insert through colony PCR. For all constructs, amplified inserts were sequenced to confirm cloning of the correct gene fragment.

\section{DNA sequencing and sequence analyses.}

The cDNAs as well as the recombinant clones were sequenced by primer walking, using Applied Biosystems 3730 DNA Analyzer (Foster City, CA, U.S.A.). Sequences were assembled and annotated using SequencherTM 4.1 (Gene Codes Corp, Ann Arbor, MI, U.S.A.). Similarity searches were performed locally on an Apple Macintosh OSX workstation using BLAST (Altschul et al. 1997). The sequences of the PiNPP1.1, PiNPP1.2, and PiNPP1.3 cDNAs were deposited in GenBank (accession numbers AY961417, AY961431 and AY961432, respectively).

\section{Transient gene-expression assays.}

PVX agroinfection assays were performed as described by Torto and associates (2003). For routine screens, N. benthamiana plants ( 3 weeks old) at approximately the three- to fourleaf stage were used for the PVX agroinfection assays. Plants were grown and maintained in a greenhouse with an ambient temperature of 22 to $25^{\circ} \mathrm{C}$ and high light intensity. Recombinant $A$. tumefaciens GV3101 strains carrying pGR106 derivatives were streaked onto LB solid media plates containing 50 $\mathrm{mg}$ of kanamycin per milliliter and were grown for 2 to 3 days at $28^{\circ} \mathrm{C}$. Inoculations were performed on two lower leaves by dipping a wooden sterile toothpick in a culture grown on solid agar medium and then wounding each leaf twice around the main vein and near the base of the leaf. An excess of bacteria was used for the inoculations. Multiple experiments were performed, and each experiment consisted of at least four plants per construct. For comparative analyses, side-by-side inoculations on mature $N$. benthamiana (six- to eight-leaf stage) and tomato plants (4 to 6 weeks old) were performed. For each construct, two inoculations per leaf and at least three leaves per plant were used. Symptoms were documented under white light to visualize cell death or under UV light $(480 / 40 \mathrm{~nm}$ excitation filter, 510 barrier nm) to monitor the autofluorescence resulting from hypersensitive-like cell death.

For agroinfiltration, recombinant A. tumefaciens GV3101 strains were grown as described elsewhere (van der Hoorn et al. 2000), except that all culturing steps were performed in LB media. For infiltrations of silenced plants, suspensions were spun down and resuspended in MMA infiltration medium to a final $\mathrm{OD}_{600}$ of 0.8 (1 liter MMA: $5 \mathrm{~g}$ of Murashige-Skoog salts, $1.95 \mathrm{~g}$ of morpholineethanesulfonic acid [MES], $20 \mathrm{~g}$ of sucrose, $200 \mu \mathrm{M}$ acetosyringone, $\mathrm{pH}=5.6$ ). For the coexpression assays, the exact same procedures were followed except that, for the effector combinations, recombinant strains were mixed in a $1: 1$ ratio. In addition, a final $\mathrm{OD}_{600}$ of 0.2 was used for infiltration of all treatments. All suspensions were incubated 1 to $3 \mathrm{~h}$ in MMA prior to infiltration. For coinfiltration assays, at least four plants were infiltrated for each elicitor combination comparison and three to four leaves were used per plant. Infiltrated panels were scored positive (1) for occurrence of confluent necrosis or negative $(0)$ for absence of necrosis. Panels showing intermediate levels of necrosis received a score of 0.5 . The frequency of panels showing a necrotic response was determined for each treatment.

\section{TRV-induced gene silencing.}

A. tumefaciens GV3101 carrying the binary TRV RNA 1 construct pBINTRA6 and the TRV RNA2 vector pTV00 (Ratcliff et al. 2001) or pTV00 derivatives were prepared for agroinfiltration assays as described above. The bacterial suspensions were mixed in 2:1 ratio (RNA1/RNA2) in induction buffer (final $\mathrm{OD}_{600}=0.6$ ), MES $\left(10 \mathrm{~mm} \mathrm{MgCl}_{2}, 10 \mathrm{~mm} \mathrm{MES}\right.$, $\mathrm{pH}$ 5.6, and $150 \mu \mathrm{m}$ acetosyringone) and were maintained at room temperature for 2 to $3 \mathrm{~h}$. Infiltrations were conducted by gently pressing a 1-ml disposable syringe to the abaxial surface of fully expanded leaves of 3-week-old $N$. benthamiana plants, slowly depressing the plunger. A sufficient amount of bacterial suspension was used to infiltrate the leaves to give a watersoaked appearance. This typically required one to four infiltrations per leaf. Following agroinfiltration, plants were maintained in a greenhouse at $22^{\circ} \mathrm{C}$ with a 16 -h photoperiod. Secondary challenges were performed about three weeks after agroinfiltration with the TRV strains. At least four plants were infiltrated for each treatment and three to four leaves were used per plant. Infiltrated panels were scored either positive for occurrence or negative for absence of necrosis. The frequency of necrotic panels was determined for each treatment across all panels and was used to calculate percentage of necrosis.

\section{RT-PCR analyses.}

Total RNA from $P$. infestans and from infected tomato leaves was isolated, using the Trizol reagent (Gibson-BRL, Bethesda, MD, U.S.A.) according to the manufacturer instructions. First-strand cDNAs were synthesized from $4.5 \mu \mathrm{g}$ of total RNA with a universal polyT primer and the ThermoScript reverse transcriptase from the ThermoScript RT-PCR system (Gibson-BRL). Reactions were performed according to the manufacturer's instructions and were incubated at $50^{\circ} \mathrm{C}$ for $1 \mathrm{~h}$. PCR amplifications were carried out with equal amounts of cDNAs, using primer pairs PiNPP1.1-F (5'-GCGAAGCTTGA TGTGATTTCACACGATGCAGT- ${ }^{\prime}$ ) and PiNPP1.1-R (5'-GC GTCTAGACTAGCCAGCTGGACGAATAGTCCAC-3'), PiNPP1.2-F (5'-GCGAAGCTTAAAGTCAGCCGAGTCAAC CACGA-3') and PiNPP1.2-R (5'-GCGTCTAGATTAAAAAG GGAATGCATCCTCGAGT-3'), PiNPP1.3-F (5'-GCGGAAT TCCGAAGTCACGTACATCAACCACG-3') and PiNPP1.3R (5'-GCGTCTAGATCAAAACGGATAAGCATCTTTCAG-3'). Integrity of the mRNA and cDNA was controlled with primers EF2-F1 (5'-TGACGCTATCGCCAAGGAATC-3') and EF2-R1 
(5'-TAACGCTGAGCCGTAATGGGGG-3'), which are specific for the constitutive elongation factor 2 alpha (ef2) gene of $P$. infestans (Torto et al. 2002).

\section{ACKNOWLEDGMENTS}

We thank I. Malcuit and D. Baulcombe for providing PVX and TRV vectors, D. Qutob and M. Gijzen for the PsojNIP and Nep1 constructs, K. Posthuma and G. Van den Ackerveken for providing the p35S-PsojNIP construct, T. Meulia for DNA sequencing, and J. Win for critically reading the manuscript. This work was supported by a National Science Foundation Plant Genome Research Program grant DBI-0211659. Salaries and research support were provided, in part, by state and federal funds appropriated to the Ohio Agricultural Research and Development Center, The Ohio State University.

\section{LITERATURE CITED}

Aarts N., Metz M., Holub E., Staskawicz B. J., Daniels M. J., and Parker J. E. 1998. Different requirements for EDS1 and NDR1 by disease resistance genes define at least two $R$ gene-mediated signaling pathways in Arabidopsis. Proc. Natl. Acad. Sci. U.S.A. 95:10306-10311.

Altschul, S. F., Madden, T. L., Schaffer, A. A., Zhang, J., Zhang, Z., Miller, W., and Lipman, D. J. 1997. Gapped BLAST and PSI-BLAST: A new generation of protein database search programs. Nucleic Acids Res. 25:3389-3402.

Asai, T., Stone, J. M., Heard, J. E., Kovtun, Y., Yorgey, P., Sheen, J., and Ausubel, F. M. 2000. Fumonisin B1-induced cell death in Arabidopsis protoplasts requires jasmonate-, ethylene-, and salicylate-dependent signaling pathways. Plant Cell 12:1823-1836.

Austin, M. J., Muskett, P., Kahn K., Feys, B. J., Jones, J. D. G., and Parker, J. E. 2002. Regulatory role of SGT1 in early $R$ gene-mediated plant defenses. Science 295:2077-2080.

Azevedo, C., Sadanandom, A., Kitagawa, K., Freialdenhoven, A., Shirasu, K., and Schulze-Lefert, P. 2002. The RAR1 interactor SGT1, an essential component of $R$ gene-triggered disease resistance. Science 295:2073-2076.

Bailey, B. A. 1995. Purification of a protein from culture filtrates of Fusarium oxysporum that induces ethylene and necrosis in leaves of Erythroxylum coca. Phytopathology 85:1250-1255.

Bailey, B. A., Jennings, J. C., and Anderson, J. D. 1997. The 24-kDa protein from Fusarium oxysporum f. sp. erythroxyli: Occurrence in related fungi and the effect of growth medium on its production. Can. J. Microbiol. 43:45-55.

Bell, K. S., Sebaihia, M., Pritchard, L., Holden, M. T. G., Hyman, L. J., Holeva, M. C., Thomson, N. R., Bentley, S. D., Churcher, L. J. C., Mungall, K., Atkin, R., Bason, N., Brooks, K., Chillingworth, T., Clark, K., Doggett, J., Fraser, A., Hance, Z., Hauser, H., Jagels, K., Moule, S., Norbertczak, H., Ormond, D., Price, C., Quail, M. A., Sanders, M., Walker, D., Whitehead, S., Salmond, G. P. C., Birch, P. R. J., Parkhill J., and Toth I. K. 2004. Genome sequence of the enterobacterial phytopathogen Erwinia carotovora subsp. atroseptica and characterization of virulence factors. Proc. Natl. Acad. Sci. U.S.A. 101:11105-11110.

Bender, C. L., Alarcon-Chaidez, F., and Gross, D. C. 1999. Pseudomonas syringae phytotoxins: Mode of action, regulation, and biosynthesis by peptide and polyketide synthetases. Microbiol. Mol. Biol. Rev. 63:266-292.

Bendtsen, J. D., Nielsen, H., von Heijne, G., and Brunak, S. 2004. Improved prediction of signal peptides: SignalP 3.0. J. Mol. Biol. 340:783-795.

Block, A., Schmelz, E., Jones, J. B., and Klee, H. J. 2005. Coronatine and salicylic acid: The battle between Arabidopsis and Pseudomonas for phytohormone control. Mol. Plant Pathol. 6:79-83.

Bonas, U., and Lahaye, T. 2002. Plant disease resistance triggered by pathogen-derived molecules: Refined models of specific recognition. Curr. Opin. Microbiol. 5:44-50.

Dangl, J. L., and Jones, J. D. 2001. Plant pathogens and integrated defence responses to infection. Nature 411:826-833.

Dangl, J. L., Dietrich, R. A., and Richberg, M. H. 1996. Death don't have no mercy: Cell death programs in plant-microbe interactions. Plant Cell 8:1793-1807.

Despres, C., DeLong, C., Glaze, S., Liu, E., and Fobert, P. R. 2000. The Arabidopsis NPR1/NIM1 protein enhances the DNA binding activity of a subgroup of the TGA family of bZIP transcription factors. Plant Cell 12:279-290.

Despres, C., Chubak, C., Rochon, A., Clark, R., Bethune, T., Desveaux, D., and Fobert, P. R. 2003. The Arabidopsis NPR1 disease resistance protein is a novel cofactor that confers redox regulation of DNA binding activity to the basic domain/leucine zipper transcription factor TGA1. Plant Cell 15:2181-2191.
Dickman, M. B., Park, Y. K., Oltersdorf, T., Li, W., Clemente, T., and French, R. 2001. Abrogation of disease development in plants expressing animal antiapoptotic genes. Proc. Natl. Acad. Sci. U.S.A. 98:69576962.

Ekengren, S. K., Liu, Y., Schiff, M., Dinesh-Kumar, S. P., and Martin, G. B. 2003. Two MAPK cascades, NPR1, and TGA transcription factors play a role in Pto-mediated disease resistance in tomato. Plant J. 36:905-917

Eulgem, T., Weigman, V. J., Chang, H. S., McDowell, J. M., Holub, E. B., Glazebrook, J., Zhu, T., and Dangl, J. L 2004. Gene expression signatures from three genetically separable resistance gene signaling pathways for downy mildew resistance. Plant Physiol. 135:1129-1144.

Fellbrich, G., Romanski, A., Varet, A., Blume, B., Brunner, F., Engelhardt, S., Felix, G., Kemmerling, B., Krzymowska, M., and Nurnberger, T. 2002. NPP1, a Phytophthora-associated trigger of plant defense in parsley and Arabidopsis. Plant J. 32:375-390.

Feng, S., Ma, L., Wang, X., Xie, D., Dinesh-Kumar, S. P., Wei, N., and Deng, X. W. 2003. The COP9 signalosome interacts physically with SCFCOI1 and modulates jasmonate responses. Plant Cell 15:10831094.

Feys, B. J., and Parker, J. E. 2000. Interplay of signaling pathways in plant disease resistance. Trends Genet. 16:449-455.

Feys, B., Benedetti, C. E., Penfold, C. N., and Turner, J. G. 1994. Arabidopsis mutants selected for resistance to the phytotoxin coronatine are male sterile, insensitive to methyl jasmonate, and resistant to a bacterial pathogen. Plant Cell 6:751-759.

Govrin, E. M., and Levine, A. 2000. The hypersensitive response facilitates plant infection by the necrotrophic pathogen Botrytis cinerea. Curr. Biol. 10:751-757.

Heath, M. C. 2000. Hypersensitive response-related death. Plant. Mol Biol. 44:321-334.

Huitema, E., Bos, J. I. B., Tian, M., Win, J., Waugh, M. E., and Kamoun, S. 2004. Linking sequence to phenotype in Phytophthora-plant interactions. Trends Microbiol. 12:193-200

Kamoun, S., Young, M., Glascock, C., and Tyler, B. M. 1993. Extracellular protein elicitors from Phytophthora: Host-specificity and induction of resistance to fungal and bacterial phytopathogens. Mol. Plant-Microbe Interact. 6:15-25.

Kamoun, S., van West, P., de Jong, A. J., de Groot, K. E., Vleeshouwers, V. G. A. A., and Govers, F. 1997. A gene encoding a protein elicitor of Phytophthora infestans is down-regulated during infection of potato. Mol. Plant-Microbe Interact. 10:13-20.

Kamoun, S., van West, P., Vleeshouwers, V. G., de Groot, K. E., and Govers, F. 1998. Resistance of Nicotiana benthamiana to Phytophthora infestans is mediated by the recognition of the elicitor protein INF1. Plant Cell 10:1413-1426.

Kamoun, S., Hraber, P., Sobral, B., Nuss, D., and Govers, F. 1999a. Initial assessment of gene diversity for the oomycete pathogen Phytophthora infestans based on expressed sequences. Fungal Genet. Biol. 28:94-106

Kamoun, S., Huitema, E., and Vleeshouwers, V. G. A. A. 1999b. Resistance to oomycetes: A general role for the hypersensitive response? Trends Plant Sci. 4:196-200.

Kanzaki, H., Saitoh, H., Ito, A., Fujisawa, S., Kamoun, S., Katou, S., Yoshioka, Y., and Terauchi, R. 2003. Cytosolic HSP90 and HSP70 are essential components of INF1-mediated hypersensitive response and non-host resistance to Pseudomonas cichorii in Nicotiana benthamiana. Mol. Plant Pathol. 4:383-391.

Lu, R., Malcuit, I., Moffett, P., Ruiz, M. T., Peart, J., Wu, A. J., Rathjen, J. P., Bendahmane, A., Day, L., Baulcombe, D. C. 2003. High throughput virus-induced gene silencing implicates heat shock protein 90 in plant disease resistance. EMBO (Eur. Mol. Biol. Organ.) J. 22:5690-5699.

McDowell, J. M., and Woffenden, B. J. 2003. Plant disease resistance genes: Recent insights and potential applications. Trends Biotechnol. $21: 178-183$.

Navarre, D. A., and Wolpert, T. J. 1999. Victorin induction of an apoptotic/senescence-like response in oats. Plant Cell 11:237-249.

Navarro, L., Zipfel, C., Rowland, O., Keller, I., Robatzek, S., Boller, T., and Jones, J. D. G. 2004. The transcriptional innate immune response to flg22. Interplay and overlap with Avr gene-dependent defense responses and bacterial pathogenesis. Plant Physiol. 135:1113-1128.

Niggeweg, R., Thurow, C., Weigel, R., Pfitzner, U., and Gatz, C. 2000. Tobacco TGA factors differ with respect to interaction with NPR1, activation potential and DNA-binding properties. Plant Mol. Biol. 42:775-788.

Nurnberger, T., and Brunner, F. 2002. Innate immunity in plants and animals: Emerging parallels between the recognition of general elicitors and pathogen-associated molecular patterns. Curr. Opin. Plant Biol. 5:318-324.

Peart, J. R., Lu, R., Sadanandom, A., Malcuit, I., Moffett, P., Brice, D. C., Schauser, L., Jaggard, D. A., Xiao, S., Coleman, M. J., Dow, M., Jones, 
J. D., Shirasu, K., and Baulcombe, D. C. 2002. Ubiquitin ligase-associated protein SGT1 is required for host and nonhost disease resistance in plants. Proc. Natl. Acad. Sci. U.S.A. 99:10865-10869.

Pemberton, C. L., and Salmond, G. P. C. 2004. The Nep1-like proteins-A growing family of microbial elicitors of plant necrosis. Mol. Plant Pathol. 5:353-359.

Pemberton, C. L., Whitehead, N. A., Sebaihia, M., Bell, K. S., Hyman, L. J., Harris, S. J., Matlin, A. J., Robson, N. D., Birch, P. R. J., Carr, J. P., Toth, I. K., and Salmond, G. P. 2005. Novel quorum-sensing-controlled genes in Erwinia carotovora subsp. carotovora: Identification of a fungal elicitor homologue in a soft-rotting bacterium. Mol. Plant-Microbe Interact. 18:343-353.

Qutob, D., Kamoun, S., and Gijzen, M. 2002. Expression of a Phytophthora sojae necrosis-inducing protein occurs during transition from biotrophy to necrotrophy. Plant J. 32:361-373.

Randall, T. A., Dwyer, R. A., Huitema, E., Beyer, K., Cvitanich, C., Kelkar, H., Ah Fong, A. M. V., Gates, K., Roberts, S., Yatzkan, E., Gaffney, T., Law, M., Testa, A., Torto-Alalibo, T., Zhang, M., Zheng, L., Mueller, E., Windass, J., Binder, A., Birch, P. R. J., Gisi, U., Govers, F., Gow, N. A., Mauch, F., van West, P., Waugh, M. E., Yu, J., Boller, T., Kamoun, S., Lam, S. T., and Judelson, H. 2005. Large-scale gene discovery in the oomycete Phytophthora infestans reveals likely components of phytopathogenicity shared with true fungi. Mol. Plant-Microbe Interact. 18:229-243.

Ratcliff, F., Martin-Hernandez, A. M., and Baulcombe, D. C. 2001. Tobacco rattle virus as a vector for analysis of gene function by silencing. Plant J. 25:237-245.

Sambrook, J., and Russell, D. W. 2001. Molecular Cloning : A Laboratory Manual. Cold Spring Harbor Laboratory Press, Cold Spring Harbor, N.Y., U.S.A.

Takahashi, A., Casais, C., Ichimura, K, and Shirasu, K. 2003. HSP90 interacts with RAR1 and SGT1 and is essential for RPS2-mediated disease resistance in Arabidopsis. Proc. Natl. Acad. Sci. U.S.A. 100:1177711782.

Takami, H., and Horikoshi, K. 2000. Analysis of the genome of an alkaliphilic bacillus strain from an industrial point of view. Extremophiles 4:99-108.

Torto, T. A., Rauser, L., Kamoun, S. 2002. The pipg1 gene of the oomy- cete Phytophthora infestans encodes a fungal-like endopolygalacturonase. Curr. Genet. 40:385-390.

Torto, T., Li, S., Styer, A., Huitema, E., Testa, A., Gow, N. A. R., van West, P., and Kamoun, S. 2003. EST mining and functional expression assays identify extracellular effector proteins from Phytophthora. Genome Res. 13:675-685.

Van der Hoorn, R. A. L., Laurent, F., Roth, R., and De Wit, P. J. G. M. 2000. Agroinfiltration is a versatile tool that facilitates comparative analyses of $A v r 9 / C f$-9-induced and $A v r 4 / C f$-4-induced necrosis. Mol. Plant-Microbe Interact. 13:439-446.

Veit, S., Worle, J. M., Nurnberger, T., Koch, W., and Seitz, H. U. 2001. A novel protein elicitor (PaNie) from Pythium aphanidermatum induces multiple defense responses in carrot, Arabidopsis, and tobacco. Plant Physiol. 127:832-841.

Wang, H., Li, J., Bostock, R. M., and Gilchrist, D. G. 1996. Apoptosis: A functional paradigm for programmed plant cell death induced by a hostselective phytotoxin and invoked during development. Plant Cell 8:375391.

Wang, J. Y., Cai, Y., Gou, J. Y., Mao, Y. B., Xu, Y. H., Jiang, W. H., and Chen, X. Y. 2004. VdNEP, an elicitor from Verticillium dahliae, induces cotton plant wilting. Appl. Environ. Microbiol. 70:4989-4995.

Win, J., Kanneganti, T.-D., Torto-Alalibo, T., and Kamoun, S. 2006. Computational and comparative analyses of 150 full-length cDNA sequences from the oomycete plant pathogen Phytophthora infestans. Fun. Genet. Biol. 43:20-33.

Xiang, C., Han, P., Lutziger, I., Wang, K., and Oliver, D. J.. 1999. A mini binary vector series for plant transformation. Plant Mol. Biol. 40:711-717.

Xu L., Liu F., Lechner E., Genschik P., Crosby W. L., Ma H., Peng W., Huang D., and Xie D. 2002. The SCFCOI1 ubiquitin-ligase complexes are required for jasmonate response in Arabidopsis. Plant Cell 14:19191935.

Zhang, S., Liu, Y., and Klessig, D. F. 2000. Multiple levels of tobacco WIPK activation during the induction of cell death by fungal elicitins. Plant J. 23:339-47.

Zhao, Y., Thilmony, R., Bender, C. L., Schaller, A., He, S. Y., and Howe, G. A. 2003. Virulence systems of Pseudomonas syringae pv. tomato promote bacterial speck disease in tomato by targeting the jasmonate signaling pathway. Plant J. 36:485-499. 